\title{
UNIVERSITYOF
}

FORWARD

THINKING

WESTMINSTER用

WestminsterResearch

http://www.westminster.ac.uk/westminsterresearch

\section{Effectiveness of stress relieving strategies in regulating patterns of cortisol secretion and promoting brain health}

Smyth, N., Rossi, E. and Wood, C.

NOTICE: this is the authors' version of a work that was accepted for publication in Stress and Brain Health Across the Life Course. Changes resulting from the publishing process, such as peer review, editing, corrections, structural formatting, and other quality control mechanisms may not be reflected in this document. Changes may have been made to this work since it was submitted for publication. A definitive version was subsequently published in Stress and Brain Health Across the Life Course, International Review of Neurobiology, vol. 150, pp. 219-246.

The final definitive version is available online at:

https://dx.doi.org/10.1016/bs.irn.2020.01.003

(C) 2020. This manuscript version is made available under the CC-BY-NC-ND 4.0 license https://creativecommons.org/licenses/by-nc-nd/4.0/

The WestminsterResearch online digital archive at the University of Westminster aims to make the research output of the University available to a wider audience. Copyright and Moral Rights remain with the authors and/or copyright owners. 


\title{
Running title:
}

Stress-relieving strategies and brain health

\section{Full title:}

\section{Effectiveness of stress relieving strategies in regulating patterns of cortisol secretion and promoting brain health.}

\author{
Authors: Nina Smyth ${ }^{\mathrm{a}}$, Elena Rossi ${ }^{\mathrm{a}} \&$ Carly Wood ${ }^{\mathrm{b}}$ \\ a Psychology, School of Social Sciences \\ ${ }^{\mathrm{b}}$ School of Life Sciences \\ University of Westminster \\ 115 New Cavendish St \\ London \\ Emails: \\ smythn@westminster.ac.uk \\ c.wood@westminster.ac.uk
}

Elena Rossi: w1584554@my.westminster.ac.uk

\begin{abstract}
Stress leads to ill-health and disease, and with today's fast-pace western society, engaging in strategies to relieve stress is crucial for good health across the life course. Activities such as focusing on positive characteristics, art/music therapies, mindfulness, yoga and engaging with nature and/or physical activity have been shown to reduce stress and enhance well-being. It is thought that patterns of cortisol secretion, which are regulated by the brain, are a key mediator of stress-disease and wellbeing-health links. Measurement of cortisol in saliva is a non-invasive and ecologically valid tool for detecting early changes in brain health, as well as evaluating the effectiveness of strategies in relieving stress and improving brain health as well as monitoring stress related brain changes. This chapter will review the evidence that engaging in stress relieving strategies promotes regulation and/or restoration of patterns of cortisol secretion. If such strategies are found to be effective in healthy populations, they could potentially inform ways of promoting brain health and the prevention or delay of clinical disorders involving disorders in the brain (e.g. Parkinson's Disease) and symptoms experienced with such disorders. To inform this field of research, recommendations are provided for the use of salivary cortisol as a marker of early monitoring of brain health and effectiveness of stressalleviating interventions.
\end{abstract}




\section{Stress-disease and wellbeing-health links}

Ill-being (i.e. stress, negative affect, depression) and well-being (i.e. positive emotions, psychological good health, meaning in life) are related dimensions; but importantly they are distinct. The absence of ill-being does not necessarily mean the presence of well-being; an individual might not have meaning or purpose in their lives, which is important for good health (e.g. Diener \& Emmons, 1984). Links between stress-disease and well-being-health are independent of each other and pathways mediating the associations have been shown to differ (e.g. Chida \& Steptoe, 2008; Ryff et al., 2006).

Stress results in ill-health and early death; these links are clear and well documented (for reviews, see Cuijpers \& Smit, 2002; Hemingway \& Marmot, 1999; Kubzansky \& Kawachi, 2000). A striking example of this comes from the Whitehall studies; British civil servants were studied over 10-year periods, and individuals in lower grade occupations reported the least control in their work demands and decision-making, the most effort-reward imbalance and injustice at work. These individuals were at a higher risk of ill-health for example, higher risk of coronary heart disease and mortality (e.g. Kuper \& Marmot, 2003; Marmot, Rose, Shipley, \& Hamilton, 1978). Moreover, human flourishing has been shown to be just as, if not, more important for healthy functioning. A wealth of prospective, empirical and population based research reveals benefits of well-being on health, for example, lower mortality, reduced morbidity and pain, and better self-reported health lower risk of future coronary heart disease and reduced mortality in healthy and clinical samples (Chida \& Steptoe, 2008; Kubzansky \& Thurston, 2007; Pressman \& Cohen, 2005). The study of Catholic nuns' diaries and smile intensity in photographs provide illustrative examples of the well-being-health link; positive emotional content written in the nuns' diaries and the smile intensity of baseball players predicted longevity (Abel \& Kruger, 2010; Danner, Snowdon, \& Friesen, 2001). In light of this evidence, both ill-being and well-being need consideration in order to promote healthy functioning.

\section{Cortisol: its role in health}

Cortisol is secreted during situations perceived as stressful via the hypothalamic-pituitary-adrenal (HPA) axis; higher brain regions activate the hypothalamus to secrete corticotrophin releasing hormone (CRH), triggering the release of adrenocorticotrophic hormone (ACTH) by the anterior pituitary gland, which in turn stimulates the release of cortisol from the adrenal cortex. Secretion is regulated by negative feedback; cortisol receptors in multiple brain regions detect high cortisol levels, enabling individuals to adapt and recover from stress. More importantly, cortisol regulates 24-hr function of down-stream physiological systems, controlled by the hypothalamic suprachiasmatic nucleus. A healthy pattern is characterised by a rapid increase of cortisol immediately after morning 
awakening, peaking about $30 \mathrm{~min}$ (known as the cortisol awakening response: CAR), followed by steadily declining levels thereafter (known as the diurnal decline), reaching the lowest levels in the evening/early sleep.

This dynamic cortisol pattern becomes dysregulated with chronic HPA-axis activation, which is turn results in dysregulation of multiple down-stream physiological processes, accelerating ill-health (see Smyth, Hucklebridge, Thorn, Evans, \& Clow, 2013). For example, a recent systematic review of stress responding shows that heightened and blunted responding to acute stressors in the laboratory are implicated in ill-health (Turner et al., 2020). Furthermore, a meta-analysis showed that flatter diurnal cortisol slopes over the day were predictive of a range of physical and mental ill-health outcomes, such as, cancer, depression, cardiovascular disease (Adam et al., 2017) and blunted CAR has been linked with aberrant brain health (Law \& Clow, 2020; Shi et al., 2018). Thus evidence shows that heightened and blunted (i.e. lower) stress-responding as well as high or low cortisol secretion and flattened cortisol patterns over the day are implicated in psychological and physical illhealth and cognitive deficits (see Smyth et al., 2013). However, it important to consider sex differences in the stress response system (see Smyth et al., 2013).

\section{Cortisol 'a window on the brain'; a marker of brain health}

Assessment of cortisol provides a 'window on the brain'; cortisol secretion during stressful situations has wide effects on brain structure and function and the underlying 24-hr cortisol circadian rhythm has a role in regulating other bodily systems, including brain function (Clow \& Smyth, 2020). Measurement of cortisol in saliva is non-invasive, and it is relatively easy to collect making repeated sampling from individuals in their natural environments, going about their daily lives possible. Despite its relative ease in collection, accurate measurement and consideration of variables influencing cortisol is crucial to understanding stress-disease and well-being-health links (see Smyth et al., 2013). Effects of acute stress can be measured by the examination of cortisol responses (i.e. cortisol reactivity and recovery) to stressors induced under laboratory conditions. Whilst the effects of chronic stress can be better examined by measurement of underlying basal cortisol circadian patterns.

Measuring patterns of cortisol secretion can provide a tool for enhancing and restoring brain health in healthy and clinical populations by allowing us to:

i) Detect early changes in brain health; sustained activation of the HPA-axis leads to dysregulated cortisol circadian rhythms, and deviations from 'normal' cortisol secretory patterns can be detected before manifestation of aberrant brain function and disease.

ii) Promote brain health throughout the life-course; identification of aberrant patterns of cortisol secretion (either too small or large responding to acute stressors or flattened diurnal cortisol 
patterns) can encourage strategies to restore patterns of cortisol secretion and in turn promote brain health.

iii) Evaluate effectiveness of stress relieving activities in promoting health: evaluate the effectiveness of stress-relieving activities in regulating and/or restoring patterns of cortisol secretion, and associated changes in cognition, stress/well-being and health. Cortisol has potent neurotoxic effects and restoring cortisol levels/patterns in those with aberrant levels/patterns (e.g. in brain disorder patients such as in Parkinson's disease), are likely to slow down and/or delay symptoms associated with the disorder (e.g., improvements in cognitive function which is influenced by cortisol patterns).

\section{Cortisol circadian rhythms - chronic stress exposure}

\section{i) The cortisol awakening response (CAR)}

The CAR is typically measured by collecting saliva on awakening and every $15 \mathrm{~min}$ up to $45-60 \mathrm{~min}$ post-awakening. Collecting samples at the desired time, particularly the awakening sample and consideration of state variables that influence it, is key to its accurate measurement (Law, Hucklebridge, Thorn, Evans, \& Clow, 2013; Smyth, Thorn, Hucklebridge, Clow, \& Evans, 2016; Stalder, Hucklebridge, Evans, \& Clow, 2009). The CAR is typically calculated by the mean rise (e.g. calculated as the mean increase: MnInc; area under the curve with respect to increase: AUCi; or the difference between the awakening and peak value, see Smyth et al., 2013). This measure of rise is different to overall levels in the post-awakening period (i.e. calculate mean of the 4 samples). However, more sophisticated growth curve modelling enables examination of patterns of cortisol secretion without the need to rely on composite measures, and this considered the optimal way to analyse cortisol data (see Smyth, Thorn, Hucklebridge, Clow, \& Evans, 2016)

Cortisol secretion is pulsatile with bursts approximately every hour. It is considered the first 'ultradian episode of the day'; it is the point at which the brain switches from sleeping to waking, kick-starting the ultradian rhythm. Thus it is suggested to provide additional insight into brain functioning than the profile over the rest of the day (Evans, Smyth, Thorn, Hucklebridge, \& Clow, 2019; Clow \& Smyth 2020). The CAR is thought to prepare our body to deal with upcoming demands of the day (Adam, Hawkley, Kudielka, \& Cacioppo, 2006) and has huge inter- and intra-variability; for example, a case study of a healthy male showed a range of $3.6 \mathrm{nmol} / 1$ and $39.0 \mathrm{nmol} / 1$ over 50 days (Tobias Stalder et al., 2009). This points to flexibility of the CAR to deal with daily demands (i.e. mounting a bigger rise in cortisol in the post-awakening period on more demanding days). However, most studies measure the CAR on one or two days limiting our understanding of its role 
and function. To obtain a "trait" measure of the CAR, it is recommended to measure it up to 6-days (Hellhammer et al., 2007), but this can be demanding and costly. Measuring CAR on repeated days would enable examination of flexibility of the response, and how this links with health. Recently, we showed that the shape of the CAR might be more indicative of health status than simply examining the size of the response. A significant burst of cortisol in the immediate awakening period (i.e. within $20 \mathrm{~min}$ ) followed by a steep decline in levels (termed CAR Salience) has been shown to be a better measure of CAR and health status (Evans et al., 2019). It is important to understand that flatter/blunted CAR is different from not exhibiting a CAR (i.e. a negative CAR: no rise in cortisol). It is unclear whether, a negative CAR, is an indicator of health status and requires further investigation but consideration of this issue is needed in analyses (see Clow \& Smyth 2020).

\section{The cortisol diurnal profile}

Cortisol secretion declines steadily over the day. It is typically measured by the diurnal cortisol decline; the decline from the morning (but outside of the CAR period) through to the evening as well as mean cortisol levels over the day (i.e. mean levels over relevant sample points: mean diurnal cortisol). Since awakening times vary, sample collection should be anchored to awakening time (i.e. 3, 6, 9 and $12 \mathrm{hr}$ post-awakening) and not clock time. It is essential to report both mean diurnal cortisol and diurnal cortisol decline since a flat cortisol pattern can be associated with either high or low cortisol secretion, and both are predictive of ill-health ( et al., 2017). More recently, consistency in the decline and mean levels of cortisol over days (i.e. less variation) has been shown to be important for good health (Segerstrom et al., 2017), but measurement of the profile over several days is required to examine this.

Most studies examining cortisol circadian patterns do so only by measurement of it on one or two days and restricting analyses to computing simple composite measures, thus missing valuable opportunity to examine variability of cortisol as well as drilling down on the dynamic aspects of cortisol secretion over multiple days. Moreover, the majority of studies lack longitudinal analysis, for example as little as $10 \%$ of studies (see Adam et al., 2017), thus limiting our understanding of its mediating role in stress-health and well-being-health.

\section{Stress/Cortisol responding}

Stressors can be induced under laboratory conditions; the Trier Social Stress Test (TSST:

Kirschbaum, Pirke, \& Hellhammer, 1993) includes an anticipation element, social-evaluation and uncontrollability, and these elements have been shown to most reliably activate the HPA-axis (Dickerson \& Kemeny, 2004). The TSST requires participants to prepare for a speech which they 
deliver to an unsympathetic authoritarian audience followed by a mental arithmetic task. Under laboratory conditions, this task most resembles psychosocial stress experienced in today's society. Of course, there are other types of protocols (e.g. Stroop colour-word interference task or mirror drawing) but they do not reliably activate the HPA-axis (see Wetherell et al., 2018). Cortisol levels peak about 20-30 min following onset of the stressor, returning to baseline in the following hour; to capture this wave of activity, saliva samples are collected prior to the stressor, and every 10-15 min up to 60-min from onset of the stressor (see Smyth et al., 2013). Both heightened and blunted responding are associated with a range of adverse behavioural and health outcomes in clinical and healthy populations. However, there are no normative values for a 'healthy' response, and some individuals do not respond to the stressor. It is unclear if non-responding is a trait characteristic and/or a marker of health status or simply due to timing of the stressor onset. This issue requires further investigation but should be considered in analyses and reported (see Clow \& Smyth 2020).

Despite a wealth of research showing exaggerated and blunted responding is linked with ill-health, very few studies have examined the causal effects of stress/wellbeing in the aetiology of good health and disease, as very few studies have examined negative effects of stress reactivity longitudinally (Turner et al., 2020). Moving away for longitudinal studies another way to examine causal effects is via intervention studies however; repeated measures of exposing participants to stressors can be problematic due to habituation effects (See Smyth et al., 2013). Our preliminary, unpublished data shows that if exposure to a stressor (e.g. TSST) is induced following a significant period (i.e. 6 months to 1 year) exposure to the stressor the second time still activates the HPA-axis. Thus, assigning participants to stress-relieving interventions and measuring stress reactivity at baseline and at follow-up could be a way of untangling causal effects.

\section{Stress-relieving strategies}

Today's fast past society has promoted engagement in stress-relieving strategies as a way of reducing stress and enhancing well-being. Engaging in international activities, such as focusing on positive characteristics, art/music activities, mindfulness, yoga and engaging with nature and/or physical activity, have been shown to be effective in reducing stress and enhancing well-being. The Social Prescribing initiative, in the UK, enables individuals suffering from stress-related problems and brain disorders to be referred to such activities via community and charity initiatives. For example, Neurologists work as part of a multidisciplinary team of health care professionals and some work with the Social Prescribing link worker model (see Fixsen \& Marie, in press). Evidence-based research on stress-relieving strategies in healthy and clinical population, especially those with brain disorders will promote wider scale roll out and take up of Social Prescribing in clinical and non-clinical settings. 
Examination of patterns of cortisol secretion, measured in saliva, is the ideal was to evaluate the effectiveness of stress-relieving interventions as chronic stress results in dysregulation of patterns of cortisol secretion, and this is an early marker of brain function dysregulation. Thus, it provides a 'window on the brain' in a non-invasive and ecological valid way. The next section of this chapter provides an overview of some of the evidence demonstrating the effectiveness of intentional activities in healthy regulation and/or restoration of the patterns of cortisol secretion.

\section{Positive psychological interventions}

The positive psychology movement alerted our attention to ways of enhancing well-being through engaging in intentional activities aimed at focusing on positive emotions, engagement, relationships, meaning, and accomplishments. A randomised-controlled trial of positive psychological interventions (such as expressing gratitude, identifying and using personal strengths or writing about the good things in your life, or you at your best) in adults ( $\mathrm{N}-577$, aged 35-54 years) revealed significant increases in happiness immediately and at longer follow up points; with individuals in the gratitude condition showing the largest boosts in well-being, sustained for up to one month (Seligman, Steen, Park, \& Peterson, 2005). A growing body of evidence demonstrates the effectiveness of positive psychological interventions in enhancing well-being (Boehm, Lyubomirsky, \& Sheldon, 2011), but future research will need to determine if these techniques have beneficial effects on brain function, potentially via regulation of patterns of cortisol secretion.

\section{Arts and music therapies}

The last few decades have witnessed the growth and consideration of artistic therapies such as music or visual art making/observation for management of stress; with overall beneficial effects of art therapies on stress-related outcomes being reported (Martin et al., 2018). Differing effects on the type of music has been observed for cortisol secretion; relaxing music reduces cortisol whilst stimulating music has been shown to increase it (Fancourt, Ockelford, \& Belai, 2014). Studies have revealed anxiolytic effects of music both during and post-surgical procedures in a variety of patients. For instance, Noriya Uedo et al. (2004) observed smaller increases in salivary cortisol concentrations in patients undergoing screening colonoscopy exposed to relaxing music compared to those who underwent the surgery without music. Kar, Ganguly, Roy, \& Goswami (2015) revealed similar results in patients undergoing surgery for cardiopulmonary bypass, with significantly lower secretion of cortisol secretion in those receiving the procedure whilst listening to music. Mottahedian, Sahraei, Movahhedi, Hajizadeh, \& Lak (2012) also found no increases of cortisol levels in post-operative patients exposed to music during surgery in comparison to control groups. 
Other artistic activities have been explored in association with reduced stress. For instance, Clow \& Fredhoi (2006) investigated the effect of a short lunchtime visit to an art gallery on outcomes of psychological and physiological stress in London City workers. Results showed a marked decrease in self-reported levels of stress as well as cortisol levels after the art gallery visit. Importantly, the study revealed that cortisol levels reduced significantly only for those participants whose baseline levels were already much higher than "normative" values prior to the art gallery visit. This suggests a particular role of such activities on the stress system where the latter tends to present overactive, and has important implications for enforcing these artistic activities/breaks to lower and maintain normal levels of stress, both psychologically and physiologically. Other studies on art making (e.g. drawing, painting) also reported decreasing self-reported levels of stress following being exposed to a stressor (colour-word inference test and mental arithmetic test) compared with non-artistic tasks, however, no physiological measures were obtained (Abbott, Shanahan, \& Neufeld, 2013). Although results suggest that artistic activities can lead to emotional and physiological changes with beneficial effects for health and well-being, more research is needed with attention to physiological markers such as cortisol, as well as increasing the length of interventions. This research is required to increase the current knowledge on how best to introduce art-making activities in people's lives, either through therapy or simply attending sessions; and tackle with a preventative approach to stress-related disorders and promotion of brain health.

\section{Mindfulness-based interventions}

Mindfulness, an act of consciously focusing one's attention on the present moment, in a patient and non-judgmental manner, has received a great amount of attention in recent decades. Mindfulnessbased Stress Reduction (MBSR) was one of the first clinical applications, originally implemented to alleviate suffering (Kabat-Zinn, 1982); and its application was extended to reduce stress and alleviate symptoms in those with ill-health (Grossman, Niemann, Schmidt, \& Walach, 2004). A wealth of research shows the effectiveness of mindfulness in reducing stress and enhancing well-being, however, there is less evidence on the effectiveness in restoring cortisol patterns and brain health.

A systematic review of MBSR interventions (29 studies; $N=2668$ healthy adults) observed large effects for reductions in stress (Khoury, Sharma, Rush, \& Fournier, 2015). One study measured cortisol status in adults who reported increased stress; cortisol reactivity to a psychosocial stressor (the TSST) was compared between those assigned to an 8-week MBSR intervention or waiting list control condition. No changes in cortisol concentrations between conditions or pre and post intervention were found (Nyklíček, Mommersteeg, Van Beugen, Ramakers, \& Van Boxtel, 2013), although there was a limited number of saliva samples collected and thus the peak of cortisol might 
not have been captured. Lower cortisol 30 min following awakening was observed in teachers who completed an 8-week MBSR intervention compared to those assigned to the control group (Flook, Goldberg, Pinger, Bonus, \& Davidson, 2013). Goldberg et al. (2014) found decreased hair cortisol levels following a mindfulness-based intervention in those engaged in smoking cessation treatment. Measuring cortisol in hair can be problematic since it provides a trait measure of cortisol secretion (average over 1-3 months), therefore only providing average levels and not the dynamic pattern over the day. This is problematic because both high and low cortisol levels have been associated with illhealth and it does not say anything about the pattern. High levels of cortisol could indicate high levels in the post-awakening period and declining levels over the day, which is a healthy profile, or it could mean the opposite: a flatter profile with low levels in the post-awakening period and higher levels over the reminder of the day. It is therefore important to consider these "limitations" when interpreting the data.

Mindfulness-based interventions conducted with clinical populations have also been shown to be effective in reducing self-reported stress from pre- to post-intervention and in comparison, to control groups (Mackenzie, Carlson, \& Speca, 2005; Ott, Norris, \& Bauer-Wu, 2006; Smith, Richardson, Hoffman, \& Pilkington, 2005), and some studies show sustained effects for up to 6-months (e.g. Carlson, 2018). Much of the research has been conducted on cancer patients, an ideal group to study as they experience high levels stress and aberrant cortisol profiles (e.g. Ryan et al., 2017).

Mindfulness-based interventions were most effective in reducing cortisol levels for breast cancer patients who displayed the highest cortisol levels pre intervention (Carlson, Speca, Patel, \& Goodey, 2004). Sustained effects of reducing cortisol levels were observed for up to 1-year, however, effects were less pronounced for those who had been living with cancer for a longer period (Carlson, Speca, Faris, \& Patel, 2007). There is support for lower cortisol concentrations following mindfulness-based interventions in other clinical groups; for example, lower plasma cortisol in participants with diabetes mellitus (Jung, Lee, \& Park, 2015), but in participants with inactive ulcerative colitis there were no changes in urinary cortisol concentration (Jedel et al., 2014). Like hair cortisol, urinary provides a measure of trait cortisol secretion over a 24-hr period, and not the dynamic pattern over the day. Mindfulness-based interventions have also been shown to restore cortisol circadian patterns; for example, a steeper cortisol profile over the day was observed in cancer patients randomly allocated to a mindfulness-based intervention (Carlson et al., 2013). Evidence on mindfulness-based practice as a stress-reliving activity is promising but more rigorous cortisol methodology and focus on examining changes in diurnal cortisol patterns and associated changes in stress/well-being and cognition is needed to better understand its role in brain health. Moreover, focus on a wider range of clinical brain conditions would enable examination of how changes in patterns of cortisol secretion are associated with clinical symptoms (e.g. improvements in cognition). 


\section{Yoga practice}

Yoga practice, a combination of physical postures, breathing techniques, relaxation and meditation, has increased in popularity in recent years with numerous health benefits reported (Cartwright, Mason, Porter, \& Pilkington, 2020). For example, yoga practice has been shown to reduce stress; in a systematic review of 35 studies, 25 provided support for the efficiency of yoga practice in reducing self-reported stress (Li \& Goldsmith, 2012). However, fewer studies examined the impact of yoga practice on patterns of cortisol secretion (only 8 out of 35 studies), and those that did provide conflicting evidence. For instance, the majority of the studies did not report any changes in cortisol following yoga practice (Beddoe, Yang, Kennedy, Weiss, \& Lee, 2009; Bosch, Traustadóttir, Howard, \& Matt, 2009; Schell, Allolio, \& Schonecke, 1994). In the studies that did observe lower cortisol levels following yoga practice this was for acute changes in cortisol secretion; with lower salivary cortisol following 90-min yoga practice in emotionally distressed females, college students and pregnant depressed (Field, Diego, Delgado, \& Medina, 2013; Michalsen et al., 2005; West, Otte, Geher, Johnson, \& Mohr, 2004). However, changes in cortisol levels were not always associated with changes in psychosocial measures (e.g. West et al., 2004). Few studies have examined the efficiency of yoga programmes over several weeks or months; however Rocha et al. (2012) reported that healthy Military males ( $\mathrm{N}=36$ aged 20-40 years) had lower levels of cortisol in the morning (collected at 7:00) following two 60-min weekly classes for 6-months and in comparison to the control group. Older adults $(\mathrm{N}=118$, aged 62 years) randomly assigned to three 60-min weekly classes over 8-weeks also had lower cortisol reactivity to a stressor (completion of a cognitive task) following the intervention and in comparison to the control group, and lower cortisol levels predicted better cognitive performance for the yoga group whilst increases in cortisol was predictive of worse performance in the controls (Gothe, Keswani, \& McAuley, 2016). In contrast, Granath, Ingvarsson, von Thiele, \& Lundberg (2006) did not observe reductions in cortisol concentrations following a 4month yoga intervention in adults reporting stress-related problems; however, salivary cortisol was only measured once two weeks before and after intervention.

Support for regulation of cortisol in clinical populations is mixed; no changes in urinary or salivary cortisol concentrations following a 12 week yoga programme (two 70-min weakly sessions for first 6 weeks followed by once a week for the remaining 6-weeks) were found in hypertension patients (Cohen et al., 2011). However, salivary cortisol was measured between 7:00 and 20:00 and authors did not state if time of day was consistent for pre and post salivary measures; this is a limitation as cortisol levels change over the day thus timing of its measurement needs to be consistent form pre to post measurement. Reduced cortisol concentrations in the morning and evening (collected at 6:00, 9:00 and 21:00) were observed for breast cancer patients undergoing radiotherapy $(\mathrm{N}=44)$ assigned to yoga intervention versus the control condition (Raghavendra et al., 2009) and in breast cancer patients practicing yoga twice weekly for 8-weeks (Banasik, Williams, Haberman, Blank, \& Bendel, 
2011). Different yoga practices, such as Iyengar yoga (a type of yoga that gets progressively more difficult as strength and flexibility increase), compared for example to the more classic Hatha or Ashtanga yoga, could differentially contribute to modulation of the HPA axis. Unfortunately, not all studies report the type of yoga practice being implemented, perhaps limiting a full interpretation of the findings. Additionally, studies should include an active control group (rather than the typical waitlist), which is important to exclude general effects of the activity on the outcomes measured.

Much of the evidence on the benefits of Yoga is based on average levels of cortisol, but examining cortisol circadian patterns, particularly the CAR, provides a better measure of brain-health. In individuals suffering from Fibromyalgia there were no differences in the CAR or cortisol diurnal decline, only average cortisol levels, following engagement in an 8-week yoga programme (Curtis, Osadchuk, \& Katz, 2011). However, sample size was small (N - 19) and cortisol patterns were only measured on two days; suggesting that a larger number of participants, and longer measurements are key understanding effects of yoga. Likewise, in a non-clinical MBSR intervention, yoga practice did not result in changes in CAR, diurnal decline, mean levels or serum cortisol levels despite measure of salivary cortisol over 4 days pre and post intervention (Daubenmier et al., 2011). It is suggested that yoga practice might be most effective in restoring the CAR in those chronically stressed who are exhibited blunted or exaggerated CARs (Anderson \& Wideman, 2017). However, it is difficult to make firm conclusions given the limited umber of studies examining the CAR and yoga practice.

A meta-analysis of yoga programmes (all randomised trails) revealed reductions in waking, afternoon and evening cortisol levels pre to post intervention as well as in comparison with the control groups; but sensitivity analysis suggested these reductions were moderate. Moreover, no differences in cortisol levels at $30 \mathrm{~min}$ or $60 \mathrm{~min}$ post-awakening or mid-morning, or cortisol diurnal decline were reported (Pascoe, Thompson, \& Ski, 2017). Overall the evidence on yoga practice as a stress-relieving activity is mixed mostly because of poor methodology. Future research examining the effects of yoga practice prior to exposure to a stressor in the laboratory would inform its ability to manage responses and recovery from acute stress whilst measurement of the diurnal cortisol pattern prior to and following participation in yoga practice over several months would inform its ability to regulate and/or restore cortisol circadian patterns.

\section{Physical exercise}

Being physically active is associated with healthier CAR profiles. For example, engagement in exercise restored a 'blunted CAR' to a 'healthy' and 'normal' CAR in depressed individuals (Vreeburg et al., 2009) and in police officers who experience high stress (Fekedulegn et al., 2018). Puterman et al. (2011) examined the effects of being physically active on stress responding in 46 postmenopausal women who underwent the TSST. Results clearly outlined the role of physical activity; 
sedentary participants with high levels of rumination exhibited a rapid increase of cortisol during the test, and delayed recovery of cortisol levels after the test. On the contrary, a relationship between rumination levels and cortisol patterns was absent in physically active participants.

Research in 'healthy groups' has also highlighted the role of physical exercise in reducing stress reactivity. Klaperski, von Dawans, Heinrichs, and Fuchs (2013) reported significantly increased cortisol reactivity to the TSST in sedentary individuals, compared to moderately and vigoursly active individuals. Furthermore, a 12-week endurance exercise programme resulted in significantly reduced cortisol reactivity to the TSST (Klaperski, von Dawans, Heinrichs, \& Fuchs, 2014). These changes were significantly different to those experienced by the waiting control and relaxation groups; however, the relaxation group also experienced a reduction in cortisol reactivity following the relaxation intervention. Notably, the exercise group were the only group to experience changes in their physical fitness over the course of the intervention; suggesting a potential role of fitness in reducing stress reactivity. This is supported by the findings of Wood, Clow, Hucklebridge, Law, \& Smyth (in review) who reported reduced overall cortisol responses to the TSST in 'fit' compared to 'unfit' individuals. However, much of the evidence on the effects of physical fitness is focused on athletic populations and does not use gold-standard methods of fitness assessment such as the $\mathrm{VO}_{2}$ max test; limiting the interpretation of findings to the wider population.

Moderate to higher-intensive physical activity is thought to prevent or delay age-related cognitive deficits via regulation of brain activity and physiological processes (Paterson \& Murias, 2014), such as regulation of patterns of cortisol secretion. For example, being physically active was associated with better cognitive function; similarly, a steeper cortisol diurnal decline was associated with better physical performance and cognitive function in adults with and without mild cognitive impairment (Dijckmans et al., 2017). However, the authors could not determine the mediating role of cortisol in the relationship between physical activity and cognitive function. In individuals with mild cognitive impairment, a 3-month exercise programme resulted in greater decline in cortisol from awakening to midday compared to the control group, but there was no difference in the CAR; additionally, improvements were seen in some aspects of cognitive and executive functions but not memory (Tortosa-Martínez et al., 2015). A strength of this study was that salivary cortisol post intervention was collected 5 days after the last exercise session, to obtain accurate stable cortisol values and to avoid reporting acute effects of physical activity on cortisol levels. Smyth et al. (2019) examined the effects of a 6-month high intensity endurance exercise program on participants with Parkinson's disease with mild cognitive impairment. Overall levels of cortisol were lower across the day, but mostly attributed to the morning, and these levels were more in line with levels exhibited by healthy adults of a similar age. Although there were a lack of observed differences in the dynamic profile of 
cortisol (i.e. CAR or diurnal decline); this might be due to measuring cortisol only on two days or it might be that aberrant cortisol patterns in Parkinson disease patients are attributed to hyper-secretion of cortisol and not changes in the dynamic of the profile. Whilst this was a small study $(\mathrm{N}=8)$, it was an intensive study and the gold standard salivary cortisol methodology was fully adhered to (i.e. electronic monitoring of saliva sampling, full measurement of cortisol circadian patterns with samples anchored to waking time); strengthening the validity of the findings.

Aerobic exercise is a form of low intensity/impact; there is mixed evidence for the relationship between aerobic exercise and cortisol patterns. For example, a 12-week aerobic or stretching programme resulted in improvements in memory for depressed patients, but results for the CAR were mixed with the aerobic group exhibiting a smaller CAR and the stretching group exhibiting a bigger CAR following the programme (Foley et al., 2008). However, this was a small sample $(\mathrm{N}=23)$ and there was large inter-individual variability in the CAR, which was measured only on one day with no control of sampling accuracy, meaning the data may be unreliable. More recently, a 6-month aerobic exercise programme resulted in restoration of a blunted CAR to a bigger increase post intervention, in healthy older adults, but changes in cortisol did not predict changes in cognition (Drogos et al., 2019). In addition, dance or movement training, as a light exercise, have been shown to be effective in reducing cortisol levels over the day, but not the dynamic of cortisol in healthy older adults (Vrinceanu et al., 2019); whilst a steeper cortisol slope over the day was found for breast cancer patients following dance movement training (Ho, Fong, \& Yip, 2018). Similarly, in Dementia patients $(\mathrm{N}=204)$ who were randomly allocated to 10 -weeks of dance movement therapy or a matched intensity exercise condition or the control group, a steeper cortisol slope over the day was observed in the dance movement group in comparison with participants in the control group, and effects were sustained at 1-year follow-up. Improvements in mood and aspects of cognitive function (i.e. retrieval and delayed recall) were also observed for participants in the dance therapy group in comparison to the control group, but no significant improvements between the exercise conditions and the control group (Ho, Fong, Chan, et al., 2018).

Of interest, single bouts of exercise are unlikely to change the CAR; two studies did not provide support for changes in CAR when exercise was carried out the day prior to the CAR measurement (Garde et al., 2009; Uçar, Özgöçer, \& Yildiz, 2018). However, single bouts of exercise might be effective in reducing overall cortisol levels; low-level physical exercise reduced cortisol levels in young adults on the Autistic Spectrum, who are considered to experience severe stress and anxiety (Hillier, Murphy, \& Ferrara, 2011).

Evidence on physical activity in promoting brain health is more advanced than other activities reviewed, mainly because more rigours research has been conducted. Many studies point to the 
effectiveness of physical activity in managing responses to stress as well as regulating and restoring cortisol circadian patterns. Moreover, this evidence comes from both healthy and clinical populations, and what is exciting is that evidence points to changes in patterns of cortisol secretion is related with other improvements in brain health, such as cognitive function. To further advance this area longitudinal analysis of physical activity in healthy populations and intervention studies involving a range of brain disorders is needed using optimal measurement of cortisol alongside measurement of improvements in health and/or clinical symptoms.

\section{Nature and physical activity}

Exposure and access to natural environments reduces stress and is associated with many health benefits (Barton, Bragg, Wood, \& Pretty, 2016). Earlier studies revealed that salivary cortisol levels were lower for participants who were shown scenes of nature or exposed to natural environments (e.g. walking in a forest) compared to those exposed to urban scenes or environments (e.g. Beil \& Hanes, 2013; Lee, Park, Tsunetsugu, Kagawa, \& Miyazaki, 2009; Park et al., 2007). Exposure to a stressor in the laboratory, a stressful version of the Stroop Test, resulted in lower cortisol levels in allotment gardeners that were randomly assigned to outdoor gardening compared to those who read a book indoors (Van Den Berg \& Custers, 2010). Although results are promising, most of these studies are conducted on small samples; nonetheless support was provided for reduced cortisol levels from a larger study of 280 participants who visited forests or city environments on different days; salivary cortisol was lower when they visited the forest environments compared to when they visited the city areas (Park, Tsunetsugu, Kasetani, Kagawa, \& Miyazaki, 2009).

Growing evidence supports healthier cortisol circadian rhythms in those who have more access to natural environments. For example, more green-space in the neighbourhood was associated with a steeper cortisol decline over the day in unemployed adults ( $\mathrm{N}=25$, aged 35-55 years) living in deprived areas. Although they exhibited cortisol levels within the expected 'healthy' range, they exhibited a flattened profile, with low levels of cortisol in the morning and little decline over the day, meaning higher levels later in the day. This highlights the importance of examining diurnal patterns over the day since average levels of cortisol were within the expected range but by examining day patterns, we can see that levels are low when they should be higher, and vice versa (Ward Thompson et al., 2012). To extend these findings, Roe et al. (2013) examined the importance of neighbourhood green space in a larger sample $(\mathrm{N}=106)$ and observed differences in this relationship for males and females; females with little green space in their neighbourhood, showed a low and flat cortisol slope (i.e. low levels of cortisol over the day with little decline from morning to the evening) whilst males with little green-space in their neighbourhood showed a high and flat cortisol profile (i.e. high levels over the day with little decline from morning to evening). These findings highlight the need to 
examine males and females separately as we cannot assume that stress-relieving activities will have the same effects for males and females.

Access and exposure to natural environments encourages physical activity, and physical activity in natural environments (i.e. Green Exercise) provides additional benefits for health and well-being than nature exposure or physical activity alone (see Barton et al., 2016). A systematic review of 43 studies using a variety of designs (i.e. comparison between participants allocated to different conditions or comparing participants who completed all conditions on different days or weeks), across a range of countries and settings demonstrated the benefits of exposure to nature and green exercise in reducing stress and cortisol concentrations, with natural environments having the most benefits in reducing stress (Kondo, Jacoby, \& South, 2018). But changes in cortisol were at times independent of changes in psychosocial variables and sometimes no changes in cortisol were observed whilst changes in psychosocial measures were. Fewer studies have examined green exercise and cortisol circadian rhythms but a work-based green-exercise ( 25 min bike session and 20 min strength session) programme was shown to restore the CAR in 14 office-workers; CAR was heightened, outside of the expected range prior to the intervention and was lower post-intervention compared to those that exercised indoors (Calogiuri et al., 2015).

Recently, we conducted a study to examine the efficiency of an outdoor walk in regulating our response to stress. Healthy young females completed a $30 \mathrm{~min}$ walk prior to being exposed to the group version of the TSST; and exhibited significantly lower levels of cortisol in comparison to healthy females who did not go for a walk (Wood et al., 2018). No differences were observed for cortisol reactivity; however, this pilot study did not account for cortisol non-responders. Furthermore, the walk consisted of walking through an urban area to access a green environment, thus we could not determine if a nature-based walk was more beneficial than a walk in a non-nature environment as the exact effects of the green exercise could not be determined. To untangle the effects of green-exercise on stress, we conducted a well-controlled and intensive study where 18 healthy adults completed a 30min treadmill exercise at $50 \%$ of their $\mathrm{VO}_{2}$ max whilst viewing a nature, built or blank screen. Participants in the urban exercise conditions exhibited a 'blunted' cortisol response and reported higher stress. Although a small study $(\mathrm{N}=18)$, exercise intensity was based on individual's fitness levels ensuring that exercise intensity was carefully controlled. Results need to be confirmed in a larger sample, and when exercise is performed in a natural environment rather than whilst viewing a natural environment (Wood, Flynn, Law, Naufahu, \& Smyth, in press).

Natural environments might encourage physical activity, but with the increasing urban development access to these are decreasing and our connections with nature are changing. Thus, we need to consider individual differences in our connections with nature and the barriers to accessing it when 
considering the health benefits of nature and/or physical activity (Gladwell, Brown, Wood, Sandercock, \& Barton, 2013). Furthermore, we showed that engaging in green exercise in childhood predicted exposure and connectedness to nature in adulthood, and those with reduced stress (measured by heart rate variability) were more connected to nature (Wood \& Smyth, 2019). This finding unveils the importance of our connectedness to nature and promotes a prevention approach to intervene and educate early in childhood on the health benefits of nature and/or physical activity, which could greatly impact adult health and tackle adverse outcomes of stress.

The evidence base on engaging with nature and green exercise suggests its effective in managing our responses to stress as well as promoting healthier cortisol circadian rhythms but this evidence is limited to cross-sectional studies. Longitudinal studies examining the long-term effects of these activities is needed as well as larger scale intervention studies where exercise intensity and fitness level and our connection to nature are considered as well as the effect of social interaction, since much of these activities contain social interaction which if enjoyed is associated with healthier patterns of cortisol secretion. Studies to date have failed to examine the contributing effects of the components involved (i.e. engagement/exposure to nature, physical activity and social interaction).

\section{The importance of enjoyment and engagement in stress relieving activities}

Motivation to engage with an activity and enjoyment of that activity might promote engagement in stress relieving activities and these factors may impact the effectiveness of the activity in reducing stress, enhancing well-being and restoring an/or regulating patterns of cortisol secretion. For instance enjoyment in physical activity predicts peoples engagement in physical activity (Lewis, Williams, Frayeh, \& Marcus, 2016) and enjoyment predicts exercise level (Hagberg, Lindahl, Nyberg, \& Hellénius, 2009). Unfortunately, the majority of studies examining the effectiveness of stressrelieving strategies, did not measure these factors nor did they consider them as influencing factors. These variables could change over the course of participation in activities, thus it is important to measure these factors throughout participation in these activities to understand how they influence effectiveness of relieving stress and promoting well-being. It is also important to note that there might be individual differences in these variables and thus one activity might not be suitable for all; engaging in different activities to explore how these activities work for the individual and settling on one that is most enjoyable is likely to have the most health-related benefits. For instance, preliminary unpublished results from our group have indicated that participants' enjoyment of a range of intentional activities designed to relieve stress was a key predictor of beneficial changes in patterns of cortisol secretion in healthy adults. 


\section{Conclusions}

Evidence for the efficiency of intentional activities in alleviating stress and enhancing well-being, and in turn promoting health is promising. However, the evidence for patterns of cortisol secretion mediating the relationship between stress-disease and well-being-health is mixed; inconsistencies in results might be driven by differences in methodology, insufficient power due to small samples, study design, lack of control groups and/or randomization, and type of analysis. The majority of studies are limited to examining changes in cortisol concentrations, but both high and low cortisol levels are linked with dysregulated cortisol circadian rhythms and ill-health. Fewer studies have examined the efficiency of intentional activities in regulating and/or restoring our responses and recovery from acute stress or cortisol circadian rhythms, and those that do fail to employ rigorous measurement of cortisol that is essential for its accurate measurement. Thus, this field of research is still in its infancy and has a long way ahead before we can determine the efficiency of stress relieving activities in the regulation of patterns of cortisol secretion and in turn healthy functioning. Understanding how intentional activities can promote the prevention and/or delay of brain disorders as well as the management of clinical symptoms requires longitudinal studies across healthy populations and patients with brain disorders and examining associated changes in health/well-being and brain health (e.g. cognitive function). We have made the following recommendations for future research:

- Individuals who drop out of the intervention study might be those most in need of engaging in stress relieving activities; patterns of cortisol secretion at baseline, where possible, should be compared with those who did not drop out to understand who these interventions are most effective for.

- Measure cortisol in saliva samples since this enables measurement of stress responding or diurnal cortisol patterns over the day. Whilst other measures (i.e. urine or hair) provide trait average levels and the dynamic patterns cannot be determined.

- The consensus CAR guidelines must be adhered to for accurate measurement of the CAR (Stalder et al., 2016).

- Saliva sampling is a novel activity (can produce larger CAR on the first sampling day) and the CAR is influenced by state variables; thus measurement of CAR on 1 or 2 days is not sufficient to obtain a baseline measure of CAR. Between 3-6 days would provide a better measure of 'trait' CAR for measuring changes in CAR pre and post intervention.

- Measuring patterns of cortisol secretion on repeated days will also enable examination of appropriate variability of cortisol secretion (i.e. secretion matched to daily demands).

- Examine the cortisol rise and decline in the post-awakening period (i.e. CAR salience) and not just the size of the rise (i.e. mean rise from awakening to peak). 
- Examine both mean diurnal cortisol and cortisol decline (outside of the CAR period) as flattened profiles can be characterised by high and low cortisol levels, both associated with ill-health.

- Examine if patterns of cortisol secretion differ for males and females.

- Model the dynamic curve of cortisol (see Smyth et al., 2016) instead of using composite measures of cortisol (e.g. MnInc, AUCi), which can be influenced by inaccurate sampling.

- It is unclear whether stress non-responding and negative CARs are an indicator of health status or due to methodological issues; we should therefore report percentages of nonresponders/negative CARs, and account for these in analyses.

- Several studies do not report associations between cortisol measures and self-report measures of stress and other relevant psychosocial variables; we should measure both as either alone might fail to capture accurate reflection of individuals state.

- Measure motivation, engagement and enjoyment levels throughout the intervention, including prior to participation in the stress-reliving activity.

- Longitudinal evaluation of stress-relieving activities is required to determine the efficiency of activities in preventing stress-related changes in brain health.

- Examine if changes in patterns of cortisol secretion are related with improvements in stress and well-being, and cognitive functioning. In individuals with brain disorders also examine if changes are related with reductions and/or delay of symptoms.

- Combine cortisol measurement and health/well-being assessment alongside other ways of brain imaging. 


\section{References}

Abbott, K. A., Shanahan, M. J., \& Neufeld, R. W. J. (2013). Artistic Tasks Outperform Nonartistic Tasks for Stress Reduction. Art Therapy, 30(2), 71-78. https://doi.org/10.1080/07421656.2013.787214

Abel, E. L., \& Kruger, M. L. (2010). Smile Intensity in Photographs Predicts Longevity. Psychological Science, 21(4), 542-544. https://doi.org/10.1177/0956797610363775

Adam, E. K., Hawkley, L. C., Kudielka, B. M., \& Cacioppo, J. T. (2006). Day-to-day dynamics of experience $\{\backslash$ textendash $\}$ cortisol associations in a population-based sample of older adults. Proceedings of the National Academy of Sciences, 103(45), 17058-17063. https://doi.org/10.1073/pnas.0605053103

Adam, E. K., Quinn, M. E., Tavernier, R., McQuillan, M. T., Dahlke, K. A., \& Gilbert, K. E. (2017). Diurnal cortisol slopes and mental and physical health outcomes: A systematic review and metaanalysis. Psychoneuroendocrinology, 83, 25-41. https://doi.org/https://doi.org/10.1016/j.psyneuen.2017.05.018

Anderson, T., \& Wideman, L. (2017). Exercise and the Cortisol Awakening Response: A Systematic Review. Sports Medicine - Open, 3(1), 37. https://doi.org/10.1186/s40798-017-0102-3

Banasik, J., Williams, H., Haberman, M., Blank, S. E., \& Bendel, R. (2011). Effect of Iyengar yoga practice on fatigue and diurnal salivary cortisol concentration in breast cancer survivors. Journal of the American Academy of Nurse Practitioners, 23(3), 135-142. https://doi.org/10.1111/j.1745-7599.2010.00573.x

Barton, J., Bragg, R., Wood, C., \& Pretty, J. (2016). Green exercise: Linking nature, health and wellbeing. Routledge.

Beddoe, A. E., Yang, C.-P. P., Kennedy, H. P., Weiss, S. J., \& Lee, K. A. (2009). The Effects of Mindfulness-Based Yoga During Pregnancy on Maternal Psychological and Physical Distress. Journal of Obstetric, Gynecologic \& Neonatal Nursing, 38(3), 310-319. https://doi.org/https://doi.org/10.1111/j.1552-6909.2009.01023.x

Beil, K., \& Hanes, D. (2013). The Influence of Urban Natural and Built Environments on Physiological and Psychological Measures of Stress- A Pilot Study. International Journal of Environmental Research and Public Health, 10(4), 1250-1267. https://doi.org/10.3390/ijerph10041250

Boehm, J. K., Lyubomirsky, S., \& Sheldon, K. M. (2011). A longitudinal experimental study comparing the effectiveness of happiness-enhancing strategies in Anglo Americans and Asian Americans. Cognition and Emotion, 25(7), 1263-1272. https://doi.org/10.1080/02699931.2010.541227

Bosch, P. R., Traustadóttir, T., Howard, P., \& Matt, K. S. (2009). Functional and physiological effects of yoga in women with rheumatoid arthritis: a pilot study. Alternative Therapies in Health and 
Medicine, 15(4), 24-31. Retrieved from http://europepmc.org/abstract/MED/19623830

Calogiuri, G., Evensen, K., Weydahl, A., Andersson, K., Patil, G., Ihlebæk, C., \& Raanaas, R. K. (2015). Green exercise as a workplace intervention to reduce job stress. Results from a pilot study. Work (Reading, Mass.), 53(1), 99—111. https://doi.org/10.3233/wor-152219

Carlson, L. E. (2018). Uptake of mindfulness-based interventions: A phenomenon of wealthy white western women? Clinical Psychology: Science and Practice, 25(3), e12258. Retrieved from https://www.mendeley.com/catalogue/uptake-mindfulnessbased-interventions-phenomenonwealthy-white-western-women/

Carlson, L. E., Doll, R., Stephen, J., Faris, P., Tamagawa, R., Drysdale, E., \& Speca, M. (2013). Randomized controlled trial of mindfulness-based cancer recovery versus supportive expressive group therapy for distressed survivors of breast cancer. J Clin Oncol, 31(25), 3119-3126.

Retrieved from http://www.ksph.kz/files/journal_club/14jc/Randomized_Controlled_Trial_of_MindfulnessBased_Cancer.pdf

Carlson, L. E., Speca, M., Faris, P., \& Patel, K. D. (2007). One year pre-post intervention follow-up of psychological, immune, endocrine and blood pressure outcomes of mindfulness-based stress reduction (MBSR) in breast and prostate cancer outpatients. Brain, Behavior, and Immunity, 21(8), 1038-1049. https://doi.org/https://doi.org/10.1016/j.bbi.2007.04.002

Carlson, L. E., Speca, M., Patel, K. D., \& Goodey, E. (2004). Mindfulness-based stress reduction in relation to quality of life, mood, symptoms of stress and levels of cortisol, dehydroepiandrosterone sulfate (DHEAS) and melatonin in breast and prostate cancer outpatients. Psychoneuroendocrinology, 29(4), 448-474. https://doi.org/https://doi.org/10.1016/S0306-4530(03)00054-4

Cartwright, T., Mason, H., Porter, A., \& Pilkington, K. (2020). Yoga practice in the UK: a crosssectional survey of motivation, health benefits and behaviours. BMJ open, 10(1).

Chida, Y., \& Steptoe, A. (2008). Positive Psychological Well-Being and Mortality: A Quantitative Review of Prospective Observational Studies. Psychosomatic Medicine, 70(7).

Law, R., \& Clow, A. (in press). Stress, the cortisol awakening response and cognitive function. International Review of Neurobiology,

Clow, A., \& Smyth, N. (in press). Salivary cortisol as a non-invasive window on the brain. In International Review of Neurobiology (vol 150, in press.).

Clow, Angela, \& Fredhoi, C. (2006). Normalisation of salivary cortisol levels and self-report stress by a brief lunchtime visit to an art gallery by London City workers. Journal of Holistic Healthcare, $3(2), 29-32$.

Cohen, D. L., Bloedon, L. T., Rothman, R. L., Farrar, J. T., Galantino, M. Lou, Volger, S., ... Townsend, R. R. (2011). Iyengar Yoga versus Enhanced Usual Care on Blood Pressure in 
Patients with Prehypertension to Stage I Hypertension: a Randomized Controlled Trial. Evidence-Based Complementary and Alternative Medicine, 2011.

Cuijpers, P., \& Smit, F. (2002). Excess mortality in depression: a meta-analysis of community studies. Journal of affective disorders, 72(3), 227-236.

Curtis, K., Osadchuk, A., \& Katz, J. (2011). An eight-week yoga intervention is associated with improvements in pain, psychological functioning and mindfulness, and changes in cortisol levels in women with fibromyalgia. Journal of Pain Research, 4, 189-201. https://doi.org/10.2147/JPR.S22761

Danner, D. D., Snowdon, D. A., \& Friesen, W. V. (2001). Positive emotions in early life and longevity: findings from the nun study. Journal of Personality and Social Psychology, 80(5), 804-813. https://doi.org/10.1037//0022-3514.80.5.804

Daubenmier, J., Kristeller, J., Hecht, F. M., Maninger, N., Kuwata, M., Jhaveri, K., ... Epel, E. (2011). Mindfulness intervention for stress eating to reduce cortisol and abdominal fat among overweight and obese women: an exploratory randomized controlled study. Journal of Obesity, 2011.

Dickerson, S. S., \& Kemeny, M. E. (2004). Acute stressors and cortisol responses: a theoretical integration and synthesis of laboratory research. Psychological Bulletin, 130(3), 355-391. https://doi.org/10.1037/0033-2909.130.3.355

Diener, E., \& Emmons, R. A. (1984). The independence of positive and negative affect. Journal of Personality and Social Psychology, 47(5), 1105-1117. https://doi.org/10.1037//00223514.47.5.1105

Dijckmans, B., Tortosa-Martínez, J., Caus, N., González-Caballero, G., Martínez-Pelegrin, B., Manchado-Lopez, C., ... Clow, A. (2017). Does the diurnal cycle of cortisol explain the relationship between physical performance and cognitive function in older adults? European Review of Aging and Physical Activity, 14(1), 6. https://doi.org/10.1186/s11556-017-0175-5

Drogos, L. L., Wynne-Edwards, K., Zhou, R., Hall, S. E., Tyndall, A. V, Longman, R. S., ... Poulin, M. J. (2019). Aerobic exercise increases cortisol awakening response in older adults. Psychoneuroendocrinology, 103, 241-248. https://doi.org/https://doi.org/10.1016/j.psyneuen.2019.01.012

Evans, P., Smyth, N., Thorn, L., Hucklebridge, F., \& Clow, A. (2019). Salience versus magnitude in the measurement of the cortisol awakening response. Psychoneuroendocrinology, 103. https://doi.org/10.1016/j.psyneuen.2019.01.023

Fancourt, D., Ockelford, A., \& Belai, A. (2014). The psychoneuroimmunological effects of music: A systematic review and a new model. Brain, Behavior, and Immunity, 36, 15-26. https://doi.org/https://doi.org/10.1016/j.bbi.2013.10.014

Fekedulegn, D., Innes, K., Andrew, M. E., Tinney-Zara, C., Charles, L. E., Allison, P., ... Knox, S. S. (2018). Sleep quality and the cortisol awakening response (CAR) among law enforcement 
officers: The moderating role of leisure time physical activity. Psychoneuroendocrinology, 95, 158-169. https://doi.org/https://doi.org/10.1016/j.psyneuen.2018.05.034

Field, T., Diego, M., Delgado, J., \& Medina, L. (2013). Yoga and social support reduce prenatal depression, anxiety and cortisol. Journal of Bodywork and Movement Therapies, 17(4), 397403. https://doi.org/https://doi.org/10.1016/j.jbmt.2013.03.010

Fixsen, A., \& Marie, P. (in press). Social Prescribing for stress related disorders and brain health. In International Review of Neurobiology.

Flook, L., Goldberg, S. B., Pinger, L., Bonus, K., \& Davidson, R. J. (2013). Mindfulness for Teachers: A Pilot Study to Assess Effects on Stress, Burnout, and Teaching Efficacy. Mind, Brain, and Education, 7(3), 182-195. https://doi.org/doi:10.1111/mbe.12026

Foley, L. S., Prapavessis, H., Osuch, E. A., Pace, J. A. De, Murphy, B. A., \& Podolinsky, N. J. (2008). An examination of potential mechanisms for exercise as a treatment for depression: A pilot study. Mental Health and Physical Activity, 1(2), 69-73. https://doi.org/https://doi.org/10.1016/j.mhpa.2008.07.001

Garde, A. H., Persson, R., Hansen, Å. M., Österberg, K., Ørbæk, P., Eek, F., \& Karlson, B. (2009). Effects of lifestyle factors on concentrations of salivary cortisol in healthy individuals. Scandinavian Journal of Clinical and Laboratory Investigation, 69(2), 242-250. https://doi.org/10.1080/00365510802483708

Gladwell, V. F., Brown, D. K., Wood, C., Sandercock, G. R., \& Barton, J. L. (2013). The great outdoors: how a green exercise environment can benefit all. Extreme Physiology \& Medicine, 2(1), 3. https://doi.org/10.1186/2046-7648-2-3

Goldberg, S. B., Manley, A. R., Smith, S. S., Greeson, J. M., Russell, E., Van Uum, S., ... Davis, J. M. (2014). Hair Cortisol as a Biomarker of Stress in Mindfulness Training for Smokers. The Journal of Alternative and Complementary Medicine, 20(8), 630-634. https://doi.org/10.1089/acm.2014.0080

Gothe, N. P., Keswani, R. K., \& McAuley, E. (2016). Yoga practice improves executive function by attenuating stress levels. Biological Psychology, 121, 109-116. https://doi.org/https://doi.org/10.1016/j.biopsycho.2016.10.010

Granath, J., Ingvarsson, S., von Thiele, U., \& Lundberg, U. (2006). Stress Management: A Randomized Study of Cognitive Behavioural Therapy and Yoga. Cognitive Behaviour Therapy, 35(1), 3-10. https://doi.org/10.1080/16506070500401292

Grossman, P., Niemann, L., Schmidt, S., \& Walach, H. (2004). Mindfulness-based stress reduction and health benefits: A meta-analysis. Journal of Psychosomatic Research, 57(1), 35-43. https://doi.org/https://doi.org/10.1016/S0022-3999(03)00573-7

Hagberg, L. A., Lindahl, B., Nyberg, L., \& Hellénius, M.-L. (2009). Importance of enjoyment when promoting physical exercise. Scandinavian Journal of Medicine \& Science in Sports, 19(5), 740-747. https://doi.org/10.1111/j.1600-0838.2008.00844.x 
Hellhammer, J., Fries, E., Schweisthal, O. W., Schlotz, W., Stone, A. A., \& Hagemann, D. (2007). Several daily measurements are necessary to reliably assess the cortisol rise after awakening: State- and trait components. Psychoneuroendocrinology, 32(1), 80-86. https://doi.org/https://doi.org/10.1016/j.psyneuen.2006.10.005

Hemingway, H., \& Marmot, M. (1999). Evidence based cardiology: psychosocial factors in the aetiology and prognosis of coronary heart disease: systematic review of prospective cohort studies. BMJ: British Medical Journal, 318(7196), 1460.

Hillier, A., Murphy, D., \& Ferrara, C. (2011). A Pilot Study: Short-term Reduction in Salivary Cortisol Following Low Level Physical Exercise and Relaxation among Adolescents and Young Adults on the Autism Spectrum. Stress and Health, 27(5), 395-402. https://doi.org/10.1002/smi.1391

Ho, R. T. H., Fong, T. C. T., Chan, W. C., Kwan, J. S. K., Chiu, P. K. C., Yau, J. C. Y., \& Lam, L. C. W. (2018). Psychophysiological effects of Dance Movement Therapy and physical exercise on older adults with mild dementia: A randomized controlled trial. The Journals of Gerontology. Series B, Psychological Sciences and Social Sciences. https://doi.org/10.1093/geronb/gby145

Ho, R. T. H., Fong, T. C. T., \& Yip, P. S. F. (2018). Perceived stress moderates the effects of a randomized trial of dance movement therapy on diurnal cortisol slopes in breast cancer patients. Psychoneuroendocrinology, 87, 119-126. https://doi.org/https://doi.org/10.1016/j.psyneuen.2017.10.012

Jedel, S., Hoffman, A., Merriman, P., Swanson, B., Voigt, R., Rajan, K. B., ... Keshavarzian, A. (2014). A Randomized Controlled Trial of Mindfulness-Based Stress Reduction to Prevent Flare-Up in Patients with Inactive Ulcerative Colitis. Digestion, 89(2), 142-155. https://doi.org/10.1159/000356316

Jung, H. Y., Lee, H., \& Park, J. (2015). Comparison of the effects of Korean mindfulness-based stress reduction, walking, and patient education in diabetes mellitus. Nursing \& Health Sciences, 17(4), 516-525. https://doi.org/doi:10.1111/nhs.12229

Kabat-Zinn, J. (1982). An outpatient program in behavioral medicine for chronic pain patients based on the practice of mindfulness meditation: Theoretical considerations and preliminary results. General Hospital Psychiatry, 4(1), 33-47. https://doi.org/https://doi.org/10.1016/01638343(82)90026-3

Kar, S. K., Ganguly, T., Roy, S. S., \& Goswami, A. (2015). Effect of Indian classical music (Raga therapy) on fentanyl, vecuronium, propofol requirements and cortisol levels in cardiopulmonary bypass. J Anesth Crit Care Open Access, 2(2), 47.

Khoury, B., Sharma, M., Rush, S. E., \& Fournier, C. (2015). Mindfulness-based stress reduction for healthy individuals: A meta-analysis. Journal of Psychosomatic Research, 78(6), 519-528. https://doi.org/https://doi.org/10.1016/j.jpsychores.2015.03.009

Kirschbaum, C., Pirke, K.-M., \& Hellhammer, D. H. (1993). The 'Trier Social Stress Test' - A Tool 
for Investigating Psychobiological Stress Responses in a Laboratory Setting.

Neuropsychobiology, 28(1-2), 76-81. https://doi.org/10.1159/000119004

Klaperski, S., von Dawans, B., Heinrichs, M., \& Fuchs, R. (2013). Does the level of physical exercise affect physiological and psychological responses to psychosocial stress in women? Psychology of Sport and Exercise, 14(2), 266-274.

https://doi.org/https://doi.org/10.1016/j.psychsport.2012.11.003

Klaperski, S., von Dawans, B., Heinrichs, M., \& Fuchs, R. (2014). Effects of a 12-week endurance training program on the physiological response to psychosocial stress in men: a randomized controlled trial. Journal of Behavioral Medicine, 37(6), 1118-1133.

Kondo, M. C., Jacoby, S. F., \& South, E. C. (2018). Does spending time outdoors reduce stress? A review of real-time stress response to outdoor environments. Health \& Place, 51, 136-150. https://doi.org/https://doi.org/10.1016/j.healthplace.2018.03.001

Kubzansky, L. D., \& Thurston, R. C. (2007). Emotional Vitality and Incident Coronary Heart Disease: Benefits of Healthy Psychological Functioning. Archives of General Psychiatry, 64(12), 1393-1401. https://doi.org/10.1001/archpsyc.64.12.1393

Kubzansky, L. D., \& Kawachi, I. (2000). Going to the heart of the matter: do negative emotions cause coronary heart disease?. Journal of psychosomatic research, 48(4-5), 323-337.

Kuper, H., \& Marmot, M. (2003). Job strain, job demands, decision latitude, and risk of coronary heart disease within the Whitehall II study. Journal of Epidemiology and Community Health, 57(2), 147-153. https://doi.org/10.1136/jech.57.2.147

Law, R., Hucklebridge, F., Thorn, L., Evans, P., \& Clow, A. (2013). State variation in the cortisol awakening response. Stress, 16(5), 483-492. https://doi.org/10.3109/10253890.2013.817552

Lee, J., Park, B.-J., Tsunetsugu, Y., Kagawa, T., \& Miyazaki, Y. (2009). Restorative effects of viewing real forest landscapes, based on a comparison with urban landscapes. Scandinavian Journal of Forest Research, 24(3), 227-234. https://doi.org/10.1080/02827580902903341

Lewis, B. A., Williams, D. M., Frayeh, A., \& Marcus, B. H. (2016). Self-efficacy versus perceived enjoyment as predictors of physical activity behaviour. Psychology \& Health, 31(4), 456-469. https://doi.org/10.1080/08870446.2015.1111372

Li, A. W., \& Goldsmith, C.-A. W. (2012). The effects of yoga on anxiety and stress. Alternative Medicine Review $\square$ : A Journal of Clinical Therapeutic, 17(1), 21-35. Retrieved from http://europepmc.org/abstract/MED/22502620

Mackenzie, M. J., Carlson, L. E., \& Speca, M. (2005). Mindfulness-Based Stress Reduction (MBSR) in Oncology. Evidence-Based Integrative Medicine, 2(3), 139-145. https://doi.org/10.2165/01197065-200502030-00005

Marmot, M. G., Rose, G., Shipley, M., \& Hamilton, P. J. (1978). Employment grade and coronary heart disease in British civil servants. Journal of Epidemiology \& Community Health, 32(4), 244-249. https://doi.org/10.1136/jech.32.4.244 
Martin, L., Oepen, R., Bauer, K., Nottensteiner, A., Mergheim, K., Gruber, H., \& Koch, C. S. (2018). Creative Arts Interventions for Stress Management and Prevention-A Systematic Review. Behavioral Sciences, Vol. 8. https://doi.org/10.3390/bs8020028

Michalsen, A., Grossman, P., Acil, A., Langhorst, J., Lüdtke, R., Esch, T., ... Dobos, G. J. (2005). Rapid stress reduction and anxiolysis among distressed women as a consequence of a threemonth intensive yoga program. Medical Science Monitor $\square$ : International Medical Journal of Experimental and Clinical Research, 11(12), CR555-561. Retrieved from http://europepmc.org/abstract/MED/16319785

Mottahedian T.E., Sahraei, H., Movahhedi R.S., Hajizadeh, E., \& Lak, M. (2012). The effect of music on the level of cortisol, blood glucose and physiological variables in patients undergoing spinal anesthesia. EXCLI Journal, 11, 556-565.

Noriya Uedo, M. D., Hideki Ishikawa, M. D., Kanehisa Morimoto, M. D., Ryu Ishihara, M. D., Hiroyuki Narahara, M. D., Ikuko Akedo, M. D., ... Itaru Kaji, M. D. (2004). Reduction in salivary cortisol level by music therapy during colonoscopic examination. HepatoGastroenterology, 51, 463-465.

Nyklíček, I., Mommersteeg, P., Van Beugen, S., Ramakers, C., \& Van Boxtel, G. J. (2013). Mindfulness-based stress reduction and physiological activity during acute stress: A randomized controlled trial. Health Psychology, 32(10), 1110.

Ott, M. J., Norris, R. L., \& Bauer-Wu, S. M. (2006). Mindfulness Meditation for Oncology Patients: A Discussion and Critical Review. Integrative Cancer Therapies, 5(2), 98-108. https://doi.org/10.1177/1534735406288083

Park, B.-J., Tsunetsugu, Y., Kasetani, T., Hirano, H., Kagawa, T., Sato, M., \& Miyazaki, Y. (2007). Physiological Effects of Shinrin-yoku (Taking in the Atmosphere of the Forest)\&mdash;Using Salivary Cortisol and Cerebral Activity as Indicators\&mdash; Journal of PHYSIOLOGICAL ANTHROPOLOGY, 26(2), 123-128. https://doi.org/10.2114/jpa2.26.123

Park, B. J., Tsunetsugu, Y., Kasetani, T., Kagawa, T., \& Miyazaki, Y. (2009). The physiological effects of Shinrin-yoku (taking in the forest atmosphere or forest bathing): evidence from field experiments in 24 forests across Japan. Environmental Health and Preventive Medicine, 15(1), 18. https://doi.org/10.1007/s12199-009-0086-9

Pascoe, M. C., Thompson, D. R., \& Ski, C. F. (2017). Yoga, mindfulness-based stress reduction and stress-related physiological measures: A meta-analysis. Psychoneuroendocrinology, 86, 152 168. https://doi.org/https://doi.org/10.1016/j.psyneuen.2017.08.008

Paterson, D., \& Murias, J. (2014). Physical functioning and mental health in older adults. Physical Activity and Mental Health, Clow A, Edmunds S, Eds. Human Kinetics, Champaign, IL, 119140.

Pressman, S. D., \& Cohen, S. (2005). Does positive affect influence health? Psychological Bulletin, 131(6), 925—971. https://doi.org/10.1037/0033-2909.131.6.925 
Puterman, E., O’Donovan, A., Adler, N. E., Tomiyama, A. J., Kemeny, M., Wolkowitz, O. M., \& Epel, E. (2011). Physical activity moderates effects of stressor-induced rumination on cortisol reactivity. Psychosomatic Medicine, 73(7), 604-611.

https://doi.org/10.1097/PSY.0b013e318229e1e0

Raghavendra, R. M., Vadiraja, H. S., Nagarathna, R., Nagendra, H. R., Rekha, M., Vanitha, N., ... Kumar, V. (2009). Effects of a Yoga Program on Cortisol Rhythm and Mood States in Early Breast Cancer Patients Undergoing Adjuvant Radiotherapy: A Randomized Controlled Trial. Integrative Cancer Therapies, 8(1), 37-46. https://doi.org/10.1177/1534735409331456

Rocha, K. K. F., Ribeiro, A. M., Rocha, K. C. F., Sousa, M. B. C., Albuquerque, F. S., Ribeiro, S., \& Silva, R. H. (2012). Improvement in physiological and psychological parameters after 6months of yoga practice. Consciousness and Cognition, 21(2), 843-850. https://doi.org/https://doi.org/10.1016/j.concog.2012.01.014

Roe, J. J., Thompson, W. C., Aspinall, A. P., Brewer, J. M., Duff, I. E., Miller, D., .. Clow, A. (2013). Green Space and Stress: Evidence from Cortisol Measures in Deprived Urban Communities. International Journal of Environmental Research and Public Health, Vol. 10. https://doi.org/10.3390/ijerph10094086

Ryan, R., Clow, A., Spathis, A., Smyth, N., Barclay, S., Fallon, M., \& Booth, S. (2017). Salivary diurnal cortisol profiles in patients suffering from chronic breathlessness receiving supportive and palliative care services: A cross-sectional study. Psychoneuroendocrinology, 79. https://doi.org/10.1016/j.psyneuen.2017.01.025

Ryff, C. D., Dienberg Love, G., Urry, H. L., Muller, D., Rosenkranz, M. A., Friedman, E. M., ... Singer, B. (2006). Psychological Well-Being and Ill-Being: Do They Have Distinct or Mirrored Biological Correlates? Psychotherapy and Psychosomatics, 75(2), 85-95. https://doi.org/10.1159/000090892

Schell, F. J., Allolio, B., \& Schonecke, O. W. (1994). Physiological and psychological effects of Hatha-Yoga exercise in healthy women. International Journal of Psychosomatics $\square$ : Official Publication of the International Psychosomatics Institute, 41(1-4), 46-52. Retrieved from http://europepmc.org/abstract/MED/7843867

Segerstrom, S. C., Sephton, S. E., \& Westgate, P. M. (2017). Intraindividual variability in cortisol: Approaches, illustrations, and recommendations. Psychoneuroendocrinology, 78, 114-124.

Seligman, M. E. P., Steen, T. A., Park, N., \& Peterson, C. (2005). Positive psychology progress: empirical validation of interventions. American Psychologist, 60(5), 410.

Shi, X., Sun, X., Yao, Z., Yuan, Y., Wu, J., \& Clow, A. (2018). The cortisol awakening response predicts response inhibition in the afternoon of the same day. Psychoneuroendocrinology, 89, 23-29. https://doi.org/https://doi.org/10.1016/j.psyneuen.2017.12.016

Smith, J. E., Richardson, J., Hoffman, C., \& Pilkington, K. (2005). Mindfulness-Based Stress Reduction as supportive therapy in cancer care: systematic review. Journal of Advanced 
Nursing, 52(3), 315-327. https://doi.org/10.1111/j.1365-2648.2005.03592.x

Smyth, N., Hucklebridge, F., Thorn, L., Evans, P., \& Clow, A. (2013). Salivary cortisol as a biomarker in social science research. Social and Personality Psychology Compass, 7(9). https://doi.org/10.1111/spc3.12057

Smyth, N., Skender, E., David, F. J., Munoz, M. J., Fantuzzi, G., Clow, A., .. Corcos, D. M. (2019). Endurance exercise reduces cortisol in Parkinson's disease with mild cognitive impairment. Movement Disorders, 34(8). https://doi.org/10.1002/mds.27719

Smyth, N., Thorn, L., Hucklebridge, F., Clow, A., \& Evans, P. (2016). Assessment of the cortisol awakening response: Real-time analysis and curvilinear effects of sample timing inaccuracy. Psychoneuroendocrinology, 74. https://doi.org/10.1016/j.psyneuen.2016.09.026

Stalder, T., Kirschbaum, C., Kudielka, B. M., Adam, E. K., Pruessner, J. C., Wüst, S., ... Clow, A. (2016). Assessment of the cortisol awakening response: Expert consensus guidelines. Psychoneuroendocrinology, 63. https://doi.org/10.1016/j.psyneuen.2015.10.010

Stalder, Tobias, Hucklebridge, F., Evans, P., \& Clow, A. (2009). Use of a single case study design to examine state variation in the cortisol awakening response: Relationship with time of awakening. Psychoneuroendocrinology, 34(4), 607-614. https://doi.org/https://doi.org/10.1016/j.psyneuen.2008.10.023

Tortosa-Martínez, J., Clow, A., Caus-Pertegaz, N., González-Caballero, G., Abellán-Miralles, I., \& Saenz, M. J. (2015). Exercise Increases the Dynamics of Diurnal Cortisol Secretion and Executive Function in People With Amnestic Mild Cognitive Impairment. Journal of Aging and Physical Activity, 23(4). Retrieved from https://journals.humankinetics.com/view/journals/japa/23/4/article-p550.xml

Turner, A., Smyth, N., Hall, S., Torres, S., Hussein, M., Jayasinghe, S., ... Clow, A. (2019). How strong is the evidence linking stress reactivity with future health and disease outcomes?-A systematic review of prospective evidence. Psychoneuroendocrinology, 100, S52-S53.

Uçar, C., Özgöçer, T., \& Yildiz, S. (2018). Late-night exercise affects the autonomic nervous system activity but not the hypothalamo-pituitary-adrenal axis in the next morning. The Journal of Sports Medicine and Physical Fitness, 58(1-2), 57-65. https://doi.org/10.23736/s00224707.16.06766-9

Van Den Berg, A. E., \& Custers, M. H. G. (2010). Gardening Promotes Neuroendocrine and Affective Restoration from Stress. Journal of Health Psychology, 16(1), 3-11. https://doi.org/10.1177/1359105310365577

Vreeburg, S. A., Kruijtzer, B. P., van Pelt, J., van Dyck, R., DeRijk, R. H., Hoogendijk, W. J. G., ... Penninx, B. W. J. H. (2009). Associations between sociodemographic, sampling and health factors and various salivary cortisol indicators in a large sample without psychopathology. Psychoneuroendocrinology, 34(8), 1109-1120. https://doi.org/https://doi.org/10.1016/j.psyneuen.2009.04.024 
Vrinceanu, T., Esmail, A., Berryman, N., Predovan, D., Vu, T. T. M., Villalpando, J. M., ... Bherer, L. (2019). Dance your stress away: comparing the effect of dance/movement training to aerobic exercise training on the cortisol awakening response in healthy older adults. Stress, 22(6), 687695. https://doi.org/10.1080/10253890.2019.1617690

Ward Thompson, C., Roe, J., Aspinall, P., Mitchell, R., Clow, A., \& Miller, D. (2012). More green space is linked to less stress in deprived communities: Evidence from salivary cortisol patterns. Landscape and Urban Planning, 105(3), 221-229. https://doi.org/https://doi.org/10.1016/j.landurbplan.2011.12.015

West, J., Otte, C., Geher, K., Johnson, J., \& Mohr, D. C. (2004). Effects of hatha yoga and african dance on perceived stress, affect, and salivary cortisol. Annals of Behavioral Medicine, 28(2), 114-118. https://doi.org/10.1207/s15324796abm2802_6

Wetherell, M. A., Craw, O. \& Smith, M. A. 2018. Techniques for inducing stress: problems and opportunities. The Routledge International Handbook of Psychobiology. Routledge.

Wood, C., Flynn, M., Law, R., Naufahu, J., \& Smyth, N. (in review). The effect of the exercise environment on the response to psychological stress: a pilot study.

Wood, C. J., Clow, A., Hucklebridge, F., Law, R., \& Smyth, N. (2018). Physical fitness and prior physical activity are both associated with less cortisol secretion during psychosocial stress. Anxiety, Stress and Coping, 31(2). https://doi.org/10.1080/10615806.2017.1390083

Wood, C. J., \& Smyth, N. (2019). The health impact of nature exposure and green exercise across the life course: a pilot study. International Journal of Environmental Health Research. https://doi.org/10.1080/09603123.2019.1593327 